\title{
Reliability of rapid diagnostic test for diagnosing peripheral and placental malaria in an area of unstable malaria transmission in Eastern Sudan
}

\author{
Awadalla H Kashif ', Gamal K Adam², Ahmed A Mohmmed ${ }^{3}$, Salah E Elzaki ${ }^{4}$, Ahmed M AbdelHalim \\ and Ishag Adam ${ }^{*}$
}

\begin{abstract}
Background: Diagnosing Plasmodium falciparum malaria during pregnancy is a great challenge for clinicians because of the low density of parasites in the peripheral blood and parasite sequestration in the placenta. Nevertheless, few data on the use of malaria rapid diagnostic test (RDT) during pregnancy have been published.

Methods: P. falciparum infections were assessed in 156 febrile pregnant women by microscopic examination of their blood smears and by RDT and polymerase chain reactions (PCR). In addition, 150 women were assessed at the time of delivery by microscopy, RDT, PCR and placental histology investigations. The study was conducted at the Gadarif Hospital, Eastern Sudan. The SD Bioline P. f / P. v (Bio Standard Diagnostics, Gurgaon, Korea) RDT kit was evaluated in this study.

Results: Among the febrile pregnant women, 17 (11.0\%), 26 (16.7\%) and 18 (11.5\%) positive cases of $P$. falciparum were detected by microscopy, RDT, and PCR, respectively. The sensitivity and specificity of the microscopy was $94.4 \%$ and $100 \%$, respectively. The corresponding values for RDT evaluation were $83.3 \%$ and $92.0 \%$, as compared with PCR as the gold standard.

While there were no detected cases of malaria by microscopic examination of blood smears, 27 (18.0\%), 21(14.0\%) and 46 (30.7\%) out of the 150 placentae investigated had P. falciparum as determined by RDT, PCR, and histology, respectively. The sensitivity and specificity for RDT was $17.4 \%$ and $81.7 \%$, respectively. The corresponding values for PCR were $6.5 \%$ and $82.7 \%$, where histology was used as the gold standard.
\end{abstract}

Conclusions: The RDT kit used in this study has poor performance for peripheral and placental P. falciparum malaria detection in this setting.

Virtual slides: The virtual slide(s) for this article can be found here: http://www.diagnosticpathology.diagnomx.eu/ vs/1092363465928479

Keywords: Plasmodium falciparum, Rapid diagnostic kit, Microscopy, Placental malaria, Pregnancy

\section{Background}

Malaria is a major public health problem in the tropics. Around 125 million pregnant women live in malariaendemic areas, and 32 million of these are at risk of malaria in sub-Saharan Africa [1,2]. Sequestration of malaria parasites in the placenta, where selection of pregnancyassociated Plasmodium falciparum erythrocyte membrane protein-1 (PfEMP-1) variant surface antigen occurs in

\footnotetext{
* Correspondence: ishagadam@hotmail.com

${ }^{5}$ Faculty of Medicine, University of Khartoum, Khartoum, Sudan

Full list of author information is available at the end of the article
}

P. falciparum malaria in pregnancy, presents an enormous diagnostic challenge, especially in sub-Saharan African countries $[3,4]$.

There is a need for accurate and prompt diagnosis of malaria so as to achieve the desired level of disease control. This goal is of fundamental importance because prescription of any drug during pregnancy poses a risk to the unborn child [5]. The World Health Organization (WHO) now recommends a parasite-based diagnosis of malaria infection [6]. Microscopic examination using Giemsa-stained capillary blood slides for detection of

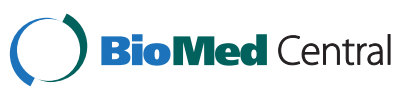


malaria parasites remains the reference standard [6]. However, blood film microscopy is time-consuming and needs significant technical skills, good-quality reagents, and clean slides; thus, its accuracy is of highly variable quality in sub-Saharan African hospitals [7-10]. Therefore, there is a need for the development of easier and faster diagnostic methods such as rapid diagnostic tests (RDTs). It has been shown that RDT is easy to use, are heat stable and have the ability to detect low parasitaemias [11]. Thus RDT is an ideal diagnostic tool for malaria diagnosis in settings that are resource constrained. While RDT have been extensively evaluated in malaria among the non-pregnant population, there are few published data on the performance of RDT for diagnosing malaria during pregnancy, especially in areas of unstable malaria transmission [12-17].

Pregnant Sudanese women are at risk of malaria regardless of their age or parity and malaria is associated with adverse maternal and perinatal outcomes [18]. RDT has not yet been implemented as standard methods for diagnosing malaria during pregnancy in Sudan. Hence, this study was conducted to investigate the performance of RDT in the diagnosis of $P$. falciparum infections in febrile pregnant women and placental malaria. This study aimed to provide evidence-based data on the best diagnostic methods for malaria during pregnancy, based on our recent observation of the limitations of the different diagnostic methods for malaria during pregnancy in Sudan [19-21].

\section{Methods}

This study was conducted at Gadarif Hospital in Eastern Sudan during September through December 2011. The area is characterized by unstable malaria transmission and $P$. falciparum is the sole malaria species present [22]. The cross-sectional study at the antenatal clinic that recruited febrile (temperature $\geq 37.5^{\circ} \mathrm{C}$ ) pregnant women, compared the accuracy of RDT with microscopy; PCR was used as a reference standard for detecting peripheral parasitaemia in the participants. At delivery, a second cross-sectional study compared the accuracy of RDT and microscopy with placental histology (the reference standard), and with PCR performed to detect placental malaria.

After signing informed consent documents, those enrolled in both studies (i.e., the pregnant and newly delivered women) were screened and clinically examined for malaria. Information was collected on social demographics using a pre-tested questionnaire. Malaria screening was performed using microscopy, RDT and PCR during pregnancy, and placental histology at delivery. Pregnant women with a confirmed diagnosis of malaria were treated with artesunate sulfadoxine-pyrimethamine which is the first line treatment for $P$. falciparum malaria in Sudan [23]. The sample sizes were calculated based on 2-sided hypothesis tests using Epi Info with $80 \%$ power and a confidence interval of $95 \%$.

\section{Rapid diagnostic testing for malaria}

The commercially available RDT kit SD Bioline P.f / P.v (Bio Standard Diagnostics, Gurgaon, Korea) was used in this study according to the manufacturer's instructions. It is used for the qualitative detection of antigens produced by $P$. falciparum $(\mathrm{Pf})$ and $P$. vivax (Pv). These antigens are the Histidine Rich Proteine-2 (PfHRP2) and lactate dehydrogenase (PvLD). Briefly a drop of whole blood $(20 \mu \mathrm{l})$ was added to the card pad followed by three drops of lysis reagent. The RDT result was read within 10 minutes and the results recorded immediately. The tests were interpreted as follows: the presence of one coloured band ( $\mathrm{C}$ control line) within the results window indicated a negative result, two coloured bands (test line 1 and $C$ line) indicated $P$. falciparum, two coloured bands (test line 2 and $C$ line) indicated $P$. vivax, while the presence of three coloured lines (test line 1 and 2 and $C$ line) indicated a mixed infection with $P$. falciparum and $P$. vivax. Tests were considered valid when there was a coloured line in the control and invalid if the control (C) failed to appear in the results window.

\section{Microscopy}

Blood smears were stained with 10\% Giemsa and examined under the X100 oil immersion objective lens of a light microscope by two independent laboratory technologists that were blinded to each other's results. The number of asexual parasites was counted against 200 leucocytes, where an average leucocyte count of $8,000 / \mu \mathrm{L}$ was assumed. Before a smear was considered negative, 200 high power fields had been examined.

\section{Placental histology}

Full thickness placental blocks (around $3 \mathrm{~cm}$ ) were taken from each placenta and kept in neutral buffered formalin

$\begin{aligned} & \text { Table } 1 \text { Mean (SD) basic characteristics of febrile } \\
& \text { pregnant women and parturient women at Gadarif } \\
& \text { Hospital, Eastern Sudan }\end{aligned}$
\begin{tabular}{lll}
\hline Variable & $\begin{array}{l}\text { Pregnant febrile women } \\
(\mathbf{N}=156)\end{array}$ & $\begin{array}{l}\text { Parturient women } \\
\mathbf{( N = 1 5 0 )}\end{array}$ \\
\hline Age, years & $27.0(6.0)$ & $26.0(6.0)$ \\
Parity & $2.1(2.1)$ & $1.6(1.7)$ \\
Gestational age, & $19.0(9.9)$ & $38.8(3.6)$ \\
weeks & & $37.4(0.5)$ \\
Temperature, ${ }^{\circ} \mathrm{C}$ & $38.2(0.5)$ & $63.1(7.5)$ \\
Weight, Kg & $62.8(6.8)$ & $10.1(1.1)$ \\
Haemoglobin, g/dl & $10.3(1.3)$ & \\
\hline
\end{tabular}


Table 2 Accuracy of microscopy and RDT in comparison with PCR for detecting malaria infection among 156 febrile pregnant women in Eastern Sudan

\begin{tabular}{|c|c|c|c|c|c|c|}
\hline \multirow[b]{3}{*}{ Microscopy } & \multirow[b]{3}{*}{ Positive } & \multicolumn{2}{|c|}{ PCR } & \multirow{2}{*}{ Total } & & \\
\hline & & Positive & Negative & & \multicolumn{2}{|c|}{ Accuracy measure $(95 \% \mathrm{Cl})$} \\
\hline & & 17 & 0 & 17 & Sensitivity & $94.4(75.5-99.7)$ \\
\hline & Negative & 1 & 138 & 139 & Specificity & $100(98.0-100.0)$ \\
\hline \multirow[t]{2}{*}{ Total } & & 18 & 138 & 156 & Positive predictive value & $100(83.4-100.0)$ \\
\hline & & & & & Negative predictive value & $99.3(96.5-100.0)$ \\
\hline \multirow[t]{2}{*}{ RDT } & Positive & 15 & 11 & 26 & Sensitivity & $83.3(61.0-95.6)$ \\
\hline & Negative & 3 & 127 & 130 & Specificity & $92.0(86.6-95.7)$ \\
\hline \multirow[t]{2}{*}{ Total } & & 18 & 138 & 156 & Positive predictive value & $57.7(38.4-75.4)$ \\
\hline & & & & & Negative predictive value & $97.7(94.0-99.4)$ \\
\hline
\end{tabular}

for histology. The buffer was used to prevent formalin pigment formation, which has similar optical characteristics and polarized light activity as malaria pigment [24]. Placental malaria infections were characterized as previously described by Bulmer et al. [25]; i.e., uninfected (no parasites or pigment), acute (parasites in intervillous spaces), chronic (parasites in maternal erythrocytes and pigment in fibrin, or cells within fibrin and/or chorionic villous syncytiotrophoblast or stroma), and past (no parasites and pigment confined to fibrin or cells within fibrin).

\section{Parasite DNA extraction and PCR}

Parasite DNA extraction and PCR assays were performed as described in our recent work [19]. Briefly, three drops of blood were collected onto a piece of filter paper from maternal peripheral blood and the maternal side of the placenta for the first and second study, respectively. These samples were air-dried and stored at ambient temperature in individual sterile plastic bags. The specimens were transported for processing and analysis in the laboratory in Khartoum. Approximately $25 \mu \mathrm{l}$ (around one third of a spot) of blood was punched out from the dried blood spots. The blood-impregnated filter paper piece was washed with distilled water and placed directly in a PCR tube containing $25 \mu \mathrm{l}$ of all of the PCR reaction components. A negative control sample containing no template DNA and an internal positive control were used for quality control purposes. Genomic DNA was checked by using an assay based on a nested PCR for P. falciparum DNA [26].

\section{Quality control}

All of the study research team were trained and had continuous supervision by the pathologist and site supervisor. RDT kits were purchased centrally and delivered to the hospital by the study team. The manufacturer's storage temperature specifications $\left(4-30^{\circ} \mathrm{C}\right)$ were adhered to by monitoring the air temperature during transportation and storage. The slide and RDT results were read by two individuals blinded to each other's results. Placental histology smears were examined by a senior pathologist, blindly

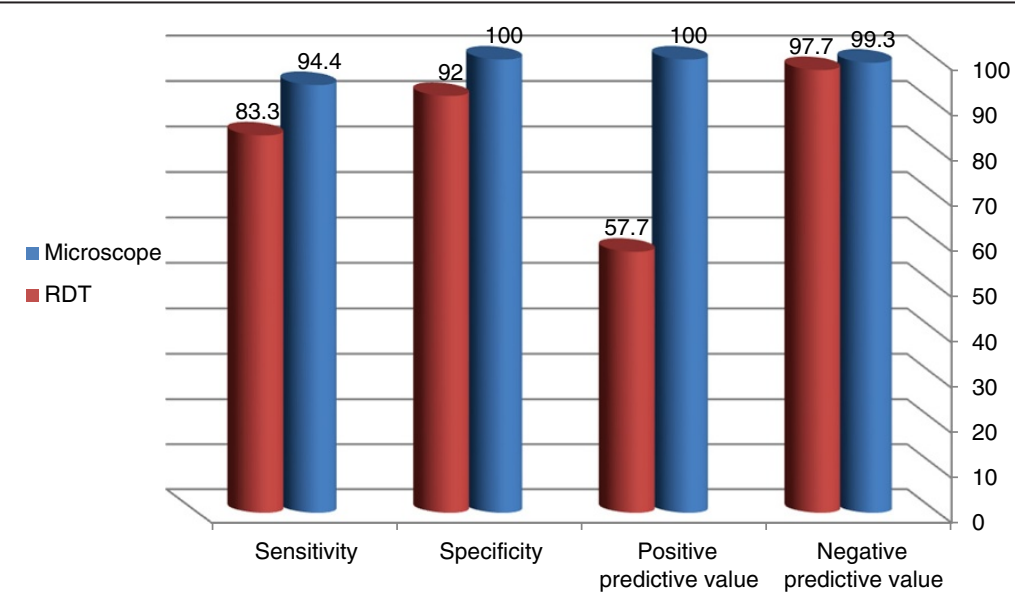

Figure 1 Accuracy of microscopy and RDT in comparison with PCR for detecting malaria infection among 156 febrile pregnant women in Eastern Sudan. 
(AAM). Likewise, the PCR was performed by the research team (AH and SA) who were blind to the microscopy, RDT, and histology results.

\section{Ethics}

The study received ethical clearance from the Research Board at the Faculty of Medical Laboratory Sciences, University of Khartoum, Sudan.

\section{Statistics}

Data were analysed using SPSS (Statistical Package for the Social Sciences) software version 19.0. Sensitivity, specificity, positive and negative predictive values were determined as described previously [27].

\section{Results}

The basic characteristics of the women enrolled in this study are shown in Table 1 . The mean (SD) of the age, gestational age and temperature for the 156 febrile pregnant women was 27.0 (6.0) years, 19.0 (10.0) weeks and $38.2^{\circ} \mathrm{C}$, respectively. Of these women, 17 (11.0\%), 26 (16.7\%) and 18 (11.5\%) were P. falciparum-positive cases as detected by microscopy, RDT and PCR, respectively. The geometric mean of the parasite counts for the microscopy results was 8897.8 (1031.0) rings/ $\mu$ l.

The sensitivity, specificity, positive predictive value (PPV) and negative predictive value (NPV) for the microscopic analyses were 94.4\%, 100\%, 100\% and 99.3\%, respectively. The corresponding values for RDT were $83.3 \%$, 92.0\%, 57.7\% and 97.7\%, where PCR was used as the gold standard, Table 2, Figure 1 and Figure 2.
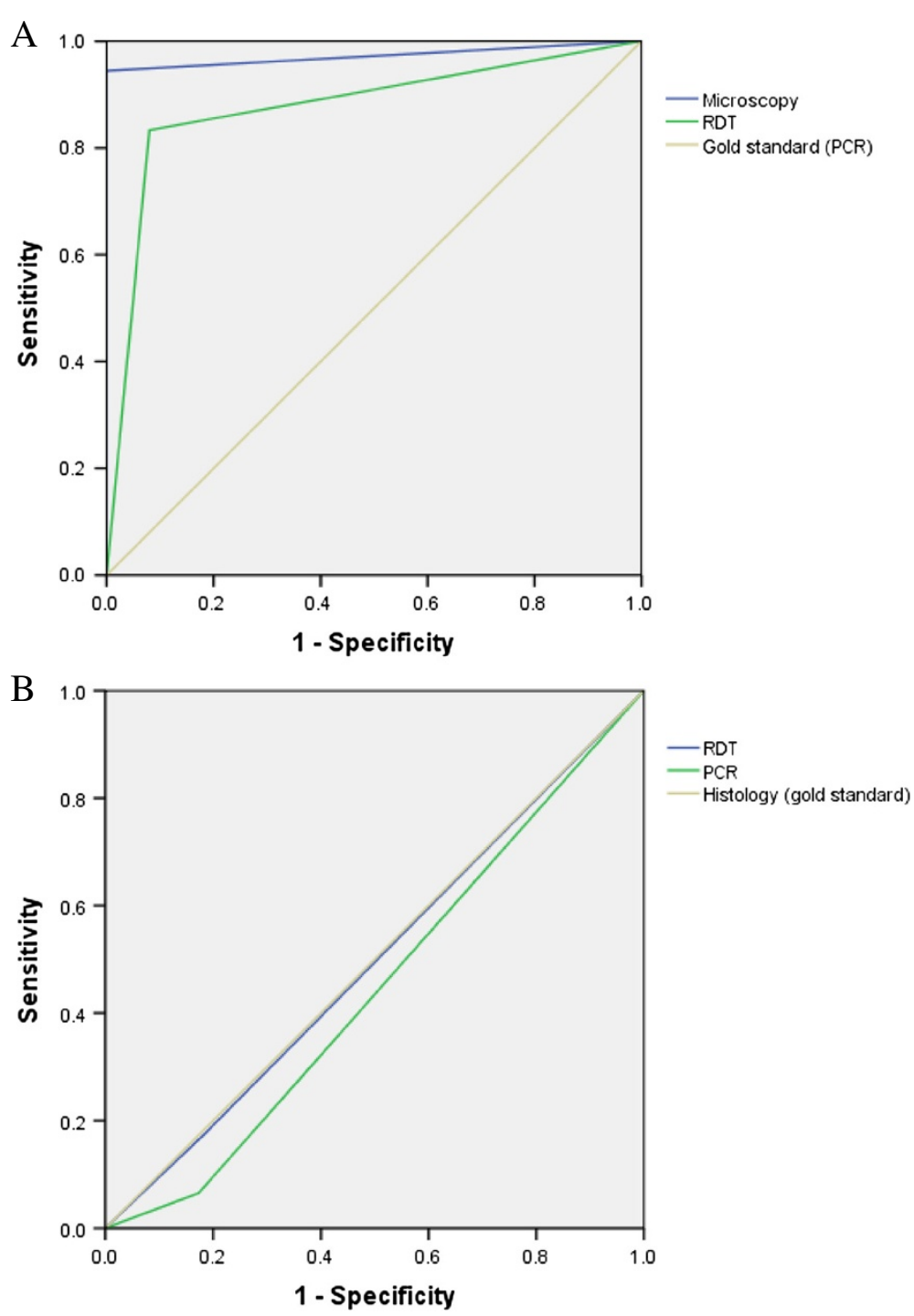

Figure 2 Comparison of receiver operator characteristic (ROC) curve for microscope RDT and PCR for diagnosing peripheral (A) and placental malaria (B). 
Table 3 Accuracy of RDT and PCR in comparison with histology for detecting placental malaria infection at Gadarif Hospital, Eastern Sudan

\begin{tabular}{|c|c|c|c|c|c|c|}
\hline \multirow[b]{3}{*}{ RDT } & \multirow[b]{3}{*}{ Positive } & \multicolumn{2}{|c|}{ Histology } & \multirow[b]{2}{*}{ Total } & \multirow{2}{*}{\multicolumn{2}{|c|}{ Accuracy measure $(95 \% \mathrm{Cl})$}} \\
\hline & & \multirow{2}{*}{$\begin{array}{l}\text { Positive } \\
8\end{array}$} & \multirow{2}{*}{$\begin{array}{l}\text { Negative } \\
19\end{array}$} & & & \\
\hline & & & & 27 & Sensitivity & $17.4(8.4-30.4)$ \\
\hline & Negative & 38 & 85 & 123 & Specificity & $81.7(73.4-88.3)$ \\
\hline \multirow[t]{2}{*}{ Total } & & 46 & 104 & 150 & Positive predictive value & $29.6(14.8-48.6)$ \\
\hline & & & & & Negative predictive value & $69.1(60.5-67.8)$ \\
\hline \multirow[t]{2}{*}{ PCR } & Positive & 3 & 18 & 21 & Sensitivity & $6.5(1.7-16.7)$ \\
\hline & Negative & 43 & 86 & 129 & Specificity & $82.7(74.5-89.0)$ \\
\hline \multirow[t]{2}{*}{ Total } & & 46 & 104 & 150 & Positive predictive value & $14.3(3.8-34.1)$ \\
\hline & & & & & Negative predictive value & $66.7(58.2-74.4)$ \\
\hline
\end{tabular}

While there were no detected cases of malaria in the microscopy examination, 27 (18.0\%), 21 (14.0\%) and 46 $(30.7 \%)$ out of the 150 placentae investigated had P. falciparum infections as judged by RDT, PCR, and histology, respectively.

The sensitivity, specificity, PPV and NPV for the RDT kit were $17.4 \%, 81.7 \%, 29.6 \%$ and $69.6 \%$, respectively. The corresponding values for PCR were 6.5\%, 82.7\%, $14.3 \%$ and $66.7 \%$, where histology was used as the gold standard, Table 3, Figure 2 and Figure 3.

Likewise, the sensitivity, specificity, PPV and NPV for the RDT kit were low $(14.3 \%, 81.4 \%, 11.1 \%$ and $85.43 \%$, respectively), where PCR was used as the gold standard, Table 4.

\section{Discussion}

The main findings of the current study were that the RDT kit had moderate sensitivity $(83.3 \%)$ and acceptable specificity (92.0\%) for the diagnosis of peripheral P. falciparum among febrile pregnant women, but low sensitivity (17.4\%) and specificity (81.7\%) for diagnosing placental malaria when compared with PCR as the gold standard.
The performance of the same brand of kit (SD Bioline P.f / P.v) was recently compared with PCR in eastern Sudan among febrile non-pregnant patients where it was found to have a sensitivity of $69 \%$ and specificity of $84 \%$ [28]. Recently low sensitivity (31.8\%) but full specificity (100\%) was reported for RDT kits used during pregnancy in Uganda, where PCR was used as the gold standard [13]. The performance of the RDT kit for malaria diagnosis used in the current study is in agreement with the findings of Schachterle et al., who showed that RDT kits had high false positive and negative rates in a region of malaria hypoendemicity in Tanzania [29]. However, the results of the later study were based on microscopy data without PCR correction. Furthermore, Mayor et al., [16] have recently shown that among the 122 women that were PCR-positive for $P$. falciparum (as judged by peripheral and/or placental blood sampling) 87 (71.3\%) and 74 $(60.7 \%)$ were not considered positive by peripheral microscopy and the HRP2 RDT, respectively.

Nevertheless, it has been observed that RDT had high sensitivity (96.8\%) and specificity (73.5\%) for the diagnosis of $P$. falciparum malaria among febrile pregnant women

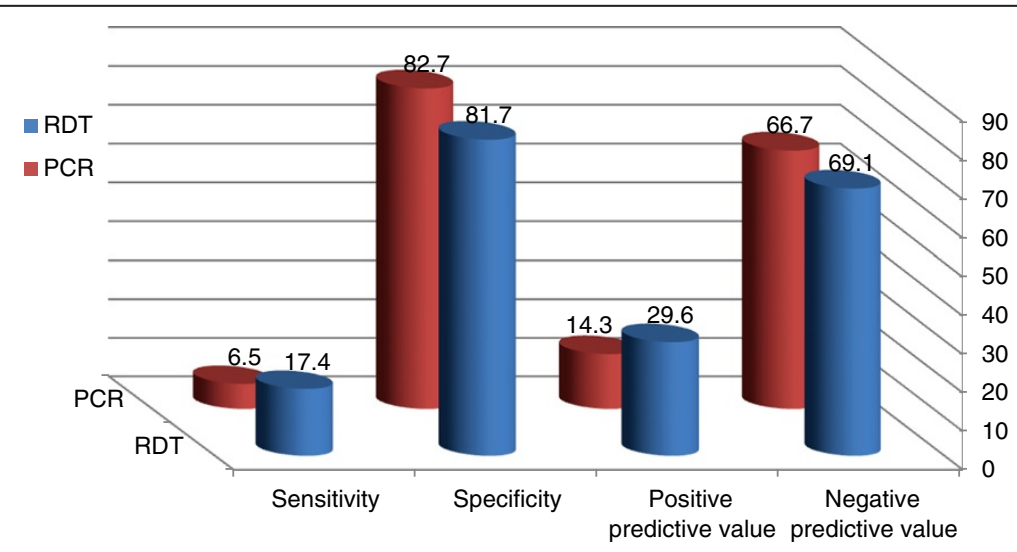

Figure 3 Accuracy of RDT and PCR in comparison with histology for detecting placental malaria infection at Gadarif Hospital, Eastern Sudan. 
Table 4 Accuracy of RDT in comparison with PCR for detecting placental malaria infection at Gadarif Hospital, Eastern Sudan

\begin{tabular}{|c|c|c|c|c|c|c|}
\hline \multirow[b]{3}{*}{ RDT } & \multirow[b]{3}{*}{ Positive } & \multicolumn{2}{|c|}{ PCR } & \multirow{3}{*}{$\begin{array}{l}\text { Total } \\
27\end{array}$} & \multirow{2}{*}{\multicolumn{2}{|c|}{$\begin{array}{c}\text { Accuracy measure } \\
(95 \% \mathrm{Cl})\end{array}$}} \\
\hline & & \multirow{2}{*}{$\begin{array}{l}\text { Positive } \\
3\end{array}$} & \multirow{2}{*}{$\begin{array}{l}\text { Negative } \\
24\end{array}$} & & & \\
\hline & & & & & Sensitivity & $\begin{array}{l}14.3 \\
(3.8-34.1)\end{array}$ \\
\hline & Negative & 18 & 105 & 123 & Specificity & $\begin{array}{l}81.4 \\
(74.0-87.4)\end{array}$ \\
\hline \multirow[t]{2}{*}{ Total } & & 21 & 129 & 150 & $\begin{array}{l}\text { Positive } \\
\text { predictive } \\
\text { value }\end{array}$ & $\begin{array}{l}11.1 \\
(3.0-27.3)\end{array}$ \\
\hline & & & & & $\begin{array}{l}\text { Negative } \\
\text { predictive } \\
\text { value }\end{array}$ & $\begin{array}{l}85.4 \\
(78.3-90.8)\end{array}$ \\
\hline
\end{tabular}

in a hyper-endemic region in Uganda, when compared with microscopy as the gold standard [15]. However, it was observed that the RDT had a modest level of accuracy (80.9\% sensitivity, $87.5 \%$ specificity) for detecting placental malaria using peripheral blood at time of delivery, in the later study [15]. Recently, the prevalence of placental infection, as determined by microscopy and RDT, was 5.1\% and $5.0 \%$, respectively, with highly significant agreement (82.9\%); however discordances were observed between the two methods at low level parasitaemias [12]. Previous studies conducted at the time of birth have shown that RDT detecting $P$. falciparum HRP2 are more sensitive than blood smears, and appear to be reliable predictors of adverse outcomes of malaria in pregnancy [30-32].

Although the manufacturer's (Bio Standard Diagnostics, Gurgaon, Korea) instructions were strictly followed, the poor performance this RDT kit in the current study is disappointing, and perhaps somewhat difficult to explain. Furthermore, the RDT used in the current study was very sensitive and specific when evaluated by WHO/ FIND [11]. High sensitivity is needed to provide confidence to the practicing physician that the RDT is unlikely to miss a malaria infection in pregnancy. However, the PPV was very low (14.3\%); this could be due to false positive results, possibly attributable to the persistent nature of HRP-2 antigenaemia that has been documented already in previous studies [33,34]. It should be mentioned that HRP2 based RDT positivity among pregnant women can persist for up to 28 days after antimalarial drug treatment, especially among women with low gravidity and those with a higher parasite density at enrolment [14]. It seems to be still there is a great challenge in diagnosing malaria and its treatment adverse effects and associated anemia [35-37].

The Sudanese National Malaria Control Programme recommends the use of RDT in those settings where no expert microscopy is available, and maintains microscopic examination in those places where microscopy is of an adequate level. This RDT strategy was investigated earlier in Sudan for the home management of malaria using artemisinin-based combination therapy [38]. Therefore, based on the findings of the current study, it appears likely that implementation of malaria RDT in Sudan in settings where microscopic expertise is available should not be recommended.

\section{Conclusions}

RDT has poor performance in detecting peripheral and placental $P$. falciparum malaria in this setting.

Competing interests

The authors declare that they have no competing interests.

\section{Authors' contributions}

AHK and IA coordinated and carried out the study, and participated in the statistical analysis and procedures. GKA and AMA participated in the clinical work and statistical analyses. AAM and SEE conducted the laboratory work. All the authors have read and approved the final version of this manuscript.

\section{Acknowledgements}

We wish to thank all of the patients for their cooperation in this study. We are very grateful to the local health authority in Gadarif State and to all of the staff of the Gadarif Maternity Hospital for their assistance. This work was funded by the National Fund for the Promotion of Medical Service,

Khartoum, Sudan.

\section{Author details}

${ }^{1}$ Faculty of Medical Laboratory Sciences, University of Khartoum, Khartoum, Sudan. ${ }^{2}$ Faculty of Medicine, University of Gadarif, Gadarif, Sudan. ${ }^{3}$ Faculty of Medicine, The National Ribat University, P.O. Box 1157, Khartoum, Sudan. ${ }^{4}$ Tropical Medicine Research Institute, National Centre for Research, Khartoum, Sudan. ${ }^{5}$ Faculty of Medicine, University of Khartoum, Khartoum, Sudan.

Received: 25 February 2013 Accepted: 8 April 2013

Published: 15 April 2013

\section{References}

1. WHO: World Malaria Report 2010. Geneva, Switzerland; 2010. Available: http:// www.who.int/malaria/world_malaria_report_2010/worldmalariareport2010.pdf.

2. Dellicour S, Tatem AJ, Guerra CA, Snow RW, ter Kuile FO: Quantifying the number of pregnancies at risk of malaria in 2007: a demographic study. PLoS Med 2010, 7:e1000221.

3. Hviid L: The role of Plasmodium falciparum variant surface antigens in protective immunity and vaccine development. Hum Vaccin 2010, 6:84-89.

4. Uneke CJ: Diagnosis of Plasmodium falciparum malaria in pregnancy in sub-Saharan Africa: the challenges and public health implications. Parasitol Res 2008, 102:333-342.

5. Bánhidy F, Lowry RB, Czeizel AE: Risk and benefit of drug use during pregnancy. Int J Med Sci 2005, 2:100-106.

6. World Health Organization (WHO) Guidelines for the treatment of malaria: Geneva. Switzerland: WHO; 2010. ISBN 9241546948.

7. Moerman F, Lengeler C, Chimumbwa J, Talisuna A, Erhart A, Coosemans M, D'Alessandro $U$ : The contribution of the health-care service to a sound and sustainable malaria-control policy. Lancet Infect Dis 2003, 3:99-102.

8. Nkrumah B, Acquah SEK, Ibrahim L, May J, Brattig N, Tannich E, Nguah SB, Adu-Sarkodie $Y$, Huenger F: Comparative evaluation of two rapid field tests for malaria diagnosis: partec rapid malaria test and binax now malaria rapid diagnostic test. BMC Infect Dis 2011, 11:143-170.

9. Nankabirwa J, Zurovac D, Njogu JN, Rwakimari JB, Counihan H, Snow RW, Tibenderana JK: Malaria misdiagnosis in Uganda-implications for policy change. Malar J 2009, 8:66.

10. McMorrow ML, Masanja Ml, Abdulla SM, Kahigwa E, Kachur SP: Challenges in routine implementation and quality control of rapid diagnostic tests for malaria-Rufiji District, Tanzania. Am J Trop Med Hyg 2008, 79:385-390. 
11. World Health Organization: Results of WHO product testing of malaria rapid diagnostic tests. In Malaria Rapid Diagnostic Test Peformance. Round 1 (2008). Geneva: World Health Organization; 2012

12. Aguilar R, Machevo S, Menéndez C, Bardají A, Nhabomba A, Alonso PL, Mayor A: Comparison of placental blood microscopy and the ICT HRP2 rapid diagnostic test to detect placental malaria. Trans $R$ Soc Trop Med Hyg 2012, 106(9):573-575.

13. Dhorda M, Piola P, Nyehangane D, Tumwebaze B, Nalusaji A, Nabasumba C, Turyakira E, McGready R, Ashley E, Guerin PJ, Snounou G: Performance of a histidine-rich protein 2 rapid diagnostic test, Paracheck $P f^{\circledR}$, for detection of malaria infections in Ugandan pregnant women. Am J Trop Med Hyg 2012, 86(1):93-95.

14. Kattenberg JH, Tahita CM, Versteeg IA, Tinto H, Traoré-Coulibaly M, Schallig $H D$, Mens PF: Antigen persistence of rapid diagnostic tests in pregnant women in Nanoro, Burkina Faso, and the implications for the diagnosis of malaria in pregnancy. Trop Med Int Health 2012, 17(5):550-557.

15. Kyabayinze DJ, Tibenderana JK, Nassali M, Tumwine LK, Riches C, Montague M, Counihan H, Hamade P, Van Geertruyden JP, Meek S: Placental Plasmodium falciparum malaria infection: operational accuracy of HRP2 rapid diagnostic tests in a malaria endemic setting. Malar J 2011, 10:306.

16. Mayor A, Moro L, Aguilar R, Bardají A, Cisteró P, Serra-Casas E, Sigaúque B, Alonso PL, Ordi J, Menéndez C: How hidden can malaria be in pregnant women? Diagnosis by microscopy, placental histology, polymerase chain reaction and detection of histidine-rich protein 2 in plasma. Clin Infect Dis 2012, 54(11):1561-1568.

17. Minja DT, Schmiegelow C, Oesterholt M, Magistrado PA, Boström S, John D, Pehrson C, Andersen D, Deloron P, Salanti A, Lemnge M, Luty AJ, Alifrangis $M$, Theander T, Lusingu JP: Reliability of rapid diagnostic tests in diagnosing pregnancy-associated malaria in north-eastern Tanzania. Malar J 2012, 11:211

18. Adam I, Elhassan EM, Haggaz AE, Ali AA, Adam GK: A perspective of the epidemiology of malaria and anaemia and their impact on maternal and perinatal outcomes in Sudan. J Infect Dev Ctries 2011, 5(2):83-87.

19. Elbashir HM, Salih MM, Elhassan EM, Mohmmed AA, Elbashir MI, Adam I: Polymerase chain reaction and histology in diagnosis of placental malaria in an area of unstable malaria transmission in Central Sudan. Diagn Pathol 2011, 6:128.

20. Elhassan EM, Haggaz AD, Magzoub MM, Adam I: Non-malarial fever among pregnant women in Medani Hospital, Sudan: Diagnostic uncertainty and overtreatment with quinine. Asian Pac J Trop Med 2010, 3:395-398.

21. Hassan S-D, Haggaz AE, Mohammed-Elhassan EB, Malik EM, Adam I: Fluorescence microscope (Cyscope) for malaria diagnosis in pregnant women in Medani Hospital, Sudan. Diagn Pathol 2011, 24:6-88.

22. Malik EM, Atta HY, Weis M, Lang A, Puta C, Lettenmaier C: Sudan Roll Back Malaria Consultative Mission: Essential Actions to Support the Attainment of the Abuja Targets, Sudan RBM Country Consultative Mission Final Report Geneva: Roll Back Malaria Partnership; 2004.

23. Adam I, Ali DM, Abdalla A: Artesunate plus Sulfadoxine-pyrimethamine in the treatment of uncomplicated $P$. falciparum malaria during pregnancy in eastern Sudan. Trans R Soc Trop Med Hyg 2006, 100:632-636.

24. Bulmer JN, Rasheed FN, Francis N, Morrison L, Greenwood BM: Placental malaria. I. Pathological classification. Histopathology 1993, 22:211-218.

25. Bulmer JN, Rasheed FN, Morrison L, Francis N, Greenwood BM: Placental malaria. II. A semi-quantitative investigation of the pathological features. Histopathology 1993, 22(3):219-225.

26. Snounou G, Viriyakosol S, Xhu XP, Jarra W, Pinhero L, Do Rosario VE, Thaithong S, Brown KN: High sensitivity of detection of human malaria parasites by use of nested polymerase chain reaction. Mol Biochem Parasitol 1993, 61:315-320.

27. Harper R, Reeves B: Reporting of precision of estimates for diagnostic accuracy: a review. BMJ 1999, 318:1322-1323.

28. Osman MM, Nour BY, Sedig MF, De Bes L, Babikir AM, Mohamedani AA, Mens PF: Informed decision-making before changing to RDT: a comparison of microscopy, rapid diagnostic test and molecular techniques for the diagnosis and identification of malaria parasites in Kassala, eastern Sudan. Trop Med Int Health 2010, 15(12):1442-1448.

29. Schachterle S, Mtove G, Levens J, Clemens EG, Shi L, Raj A, Munoz B, Reller ME, West S, Dumler SJ, Sullivan D: Prevalence and density related concordance of three diagnostic tests for malaria in hypoendemic Tanzania. J Clin Microbiol 2011, 49:3885-3891.
30. Mockenhaupt FP, Bedu-Addo G, von Gaertner C, Boye R, Fricke K, Hannibal I, Karakaya F, Schaller M, Ulmen U, Acquah PA, Dietz E, Eggelte TA, Bienzle U: Detection and clinical manifestation of placental malaria in southern Ghana. Malar J 2006, 5:119.

31. Mockenhaupt FP, Ulmen U, von Gaertner C, Bedu-Addo G, Bienzle U: Diagnosis of placental malaria. J Clin Microbiol 2002, 40:306-308.

32. Singer LM, Newman RD, Diarra A, Moran AC, Huber CS, Stennies G, Sirima SB, Konate A, Yameogo M, Sawadogo R, Barnwell JW, Parise ME: Evaluation of a malaria rapid diagnostic test for assessing the burden of malaria during pregnancy. Am J Trop Med Hyg 2004, 70:481-485.

33. Kyabayinze DJ, Tibenderana JK, Odong GW, Rwakimari JB, Counihan H: Operational accuracy and comparative persistent antigenicity of HRP2 rapid diagnostic tests for Plasmodium falciparum malaria in a hyperendemic region of Uganda. Malar J 2008, 7:221.

34. Murray CK, Gasser RA Jr, Magill AJ, Miller RS: Update on rapid diagnostic testing for malaria. Clin Microbiol Rev 2008, 21:97-110.

35. Salih MM, Mohammed AH, Mohmmed AA, Adam GK, Elbashir MI, Adam I: Monocytes and macrophages and placental malaria infections in an area of unstable malaria transmission in eastern Sudan. Diagn Pathol 2011, 6:83.

36. Adam I, Ahmed S, Mahmoud MH, Yassin Ml: Comparison of HemoCue ${ }^{\circledR}$ hemoglobin-meter and automated hematology analyzer in measurement of hemoglobin levels in pregnant women at Khartoum hospital, Sudan. Diagn Pathol 2012, 7:30.

37. Abdelrahman EG, Gasim Gl, Musa IR, Elbashir LM, Adam I: Red blood cell distribution width and iron deficiency anemia among pregnant Sudanese women. Diagn Pathol 2012, 7:168.

38. Elmardi KA, Malik EM, Abdelgadir T, Ali SH, Elsyed AH, Mudather MA Elhassan AH, Adam I: Feasibility and acceptability of home-based management of malaria strategy adapted to Sudan's conditions using artemisinin-based combination therapy and rapid diagnostic test. Malar J 2009, 8:39

doi:10.1186/1746-1596-8-59

Cite this article as: Kashif et al:: Reliability of rapid diagnostic test for diagnosing peripheral and placental malaria in an area of unstable malaria transmission in Eastern Sudan. Diagnostic Pathology 2013 8:59.

\section{Submit your next manuscript to BioMed Central and take full advantage of:}

- Convenient online submission

- Thorough peer review

- No space constraints or color figure charges

- Immediate publication on acceptance

- Inclusion in PubMed, CAS, Scopus and Google Scholar

- Research which is freely available for redistribution 